\title{
Numerical analysis and performance enhancement of compact heat exchanger using computational fluid dynamics
}

DOI : 10.36909/jer.ICIPPSD.15503

\author{
Agarwal A. *, Molwane O.B. **, Pitso I.* \\ *Department of Mechanical Engineering, FET, University of Botswana, Gaborone, Botswana. \\ ** Department of Industrial Design \& Technology, FET, University of Botswana, Gaborone, Botswana \\ *Email: agarwala@ub.ac.bw; Corresponding Author
}

\begin{abstract}
Compact heat exchangers are used in various industries due to its good efficiency and compactness. The fluid used in heat exchanger has significant effect in augmentation of heat transfer characteristics of heat exchangers. In recent years, researchers have shown keen interest in uses of nanofluids for heat exchangers due to its good thermo-physical properties. The present study explores the application of $\mathrm{ZnO} /$ water nanofluid on compact heat exchanger with circular tubes using techniques of Computational Fluid Dynamics (CFD). The CAD model is developed in Creo design software and CFD analysis is conducted using ANSYS CFX. The volume concentration of nanoparticles used for analysis are .02,.04 and .07. The CFD analysis is conducted for both laminar and turbulent flow regime using SSG shear stress turbulence model. The temperature distribution, Nusselt number and pressure plots are generated to determine heat transfer characteristics. The results are encouraging, and significant enhancement of heat transfer is achieved using $\mathrm{ZnO} /$ water nanofluid. However, the pumping power requirement also increased with increase in nanoparticle concentration.
\end{abstract}

Key words: EGR cooler, Nano fluid, heat transfer, $\mathrm{NO}_{\mathrm{x}}$ Emission, Nusselt number.

\section{INTRODUCTION}

In finned tube heat exchange, the liquid side has higher heat transfer coefficient as compared to gas side. The fins are used on gas side to increase surface area A. The condensing liquid is on one side and gas on other side (Paria et al., 2015). The geometry of finned tube heat exchanger has mostly circular tubes, rectangular tubes but sometimes elliptical tubes are also used. The fins are placed on outside and are attached using tension winding or mechanical fits as shown in figure 1 . 


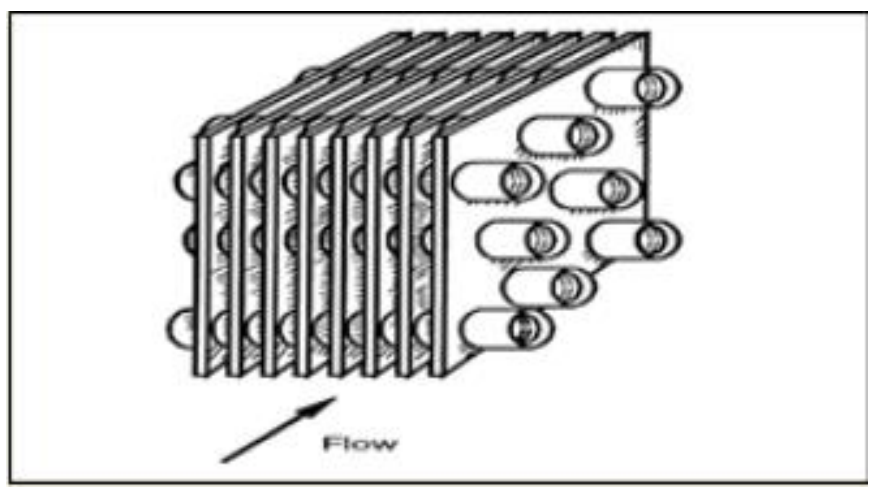

Figure 1 Finned tube heat exchanger (Paria et al. 2015)

Nanofluid, which is a "term used to describe fluids containing dispersed particles of nanoscale, can be formed from nano particles of single element (e.g. $\mathrm{Cu}, \mathrm{Fe}$, and $\mathrm{Ag}$ ), single element oxide (e.g., $\mathrm{CuO}, \mathrm{Cu} 2 \mathrm{O}, \mathrm{Al} 2 \mathrm{O} 3$, and Tio 2,), alloys (e.g., $\mathrm{Cu}-\mathrm{Zn}, \mathrm{Fe}-\mathrm{Ni}$, and Ag-Cu), multielement oxides (e.g., CuZnFe4O4, Ni Fe 2O4, and ZnFe 2O4), metal carbides (e.g., SiC, $\mathrm{B} 4 \mathrm{C}$, and $\mathrm{ZrC}$ ), metal nitrides (e.g., $\mathrm{SiN}, \mathrm{TiN}$, and $\mathrm{AlN}$ ), and carbon materials (e.g., graphite, carbon nanotubes, and diamond) suspended in water, ethanol, EG, oil, and refrigerants" (Gupta et al., 2017; Gupta, Tiwari, and Ghosh, 2018; Sundar et al., 2017). Commonly used base fluids for nano fluid formulation are water, ethylene glycol (EG), $\mathrm{EG}-\mathrm{H}_{2} \mathrm{O}$ mixtures, and oils (Suganthi and Rajan, 2017).

The nanofluids are used in sunscreen products (Burnett and Wang, 2011), medicine (Lapotko, 2009; Maier-Hauff et al., 2007), reducing buildings pollution (Kulkarni, Das, and Vajjha, 2009), magnetic sealing (Vékás, Bica, and Avdeev, 2007), microbial fuel cells (Sharma et al., 2008), anti-bacterial activity, and many other applications (Taylor et al., 2013). (Wen and Ho 2009) has investigated compounded fin, wavy fin, and plate fin for Re number ranging from 2000 to 6000 and air velocity ranging from $1 \mathrm{~m} / \mathrm{s}$ to $3 \mathrm{~m} / \mathrm{s}$. (Kusworo et al. 2020)Conducted experimental research to improve the perm-selectivity of nanohybrid polyether-sulfone membrane using NIPS method. The study shows the good results in the attachment of nano particles. The Coburn factor and fanning factor along with heat transfer coefficient and pressure drop are determined and compounded fin has shown best results among all other types. Pongsoi et al. (2013) conducted investigation on spiral fin and tube heat exchanger (L footed) with varying fin pitches. The HTC of air side and friction factor was determined for Re number ranging from 4000 to 15000 . The hot water was used as fluid and findings have shown significance of fin pitch on average HTC. Afzal, Mohammed, and Abdul (2019) has 
performed numerical investigation on shell-tube heat exchanger in parallel flow conditions. The fluids used for analysis was engine oil and water and results have shown good effectives. Nuntaphan, Kiatsiriroat, and Wang (2005) conducted investigation on 23 heat exchangers having crimpled spiral configurations with varying tube diameter, fin spacing. The findings have shown that increasing tube diameter causes increase of pressure drop and average HTC and both variables reduce with increased fin height. These results hold for inline arrangement. Su et al. (2019) has conducted CFD multiphase modelling of ANSYS fluent to simulate spray towers used in heat exchanger. The software gave reasonably accurate solutions of phase change with different turbulence models.

Pongsoi et al. (2011) investigates the crimpled finned tube heat exchanger having multi pass parallel configuration for Re number ranging from 4000 to 13000 . The effect of fin materials i.e., copper and aluminum and fin pitches on performance of air side performance is evaluated. The experimental findings have shown that fin pitch does not have any significant effect on Colburn $\mathrm{j}$ factor. The increase in friction factor is however observed at fin pitch of $6.2 \mathrm{~mm}$.

Mohammad (2021)investigated the model combustor with three struts using 2-D governing equations \& turbulence model in CFD. Sahnoune et al. (2020) performed the numerical simulation of a Newtonian Drilling Mud stream CFD based k- $\varepsilon$ model was used to study the flow properties.

In the current study $\mathrm{ZnO}$ water nanofluid is analyzed in finned tube heat exchanger using CFD. The turbulence model considered for analysis is shear stress transport and CFD analysis is conducted using ANSYS CFX software. (Agarwal and Mthembu, 2020)

\section{METHODOLOGY}

The numerical analysis of finned tube heat exchanger is conducted using techniques of computational fluid dynamics which is based on conservation of mass momentum and energy. These equations are described - Continuity Equation (Agarwal and Pitso, 2020) $\frac{D \rho}{D t}+\rho \frac{\partial U_{i}}{\partial x_{i}}=0$

Momentum equation 


$$
\underbrace{\rho \frac{\partial U_{j}}{\partial t}}_{I}+\underbrace{\rho U_{i} \frac{\partial U_{j}}{\partial x_{i}}}_{I I}=-\underbrace{\frac{\partial P}{\partial x_{j}}}_{I I I}-\underbrace{\frac{\partial \tau_{i j}}{\partial x_{i}}}_{I V}+\underbrace{\rho g_{j}}_{V}
$$

"I: Local change with time, II: Momentum convection, III: Surface force, IV Moleculardependent momentum exchange (diffusion), V: Mass force” (Agarwal, Molwane, and Pitso, 2021)

Energy Equation (Agarwal, Molwane, and Pitso, 2021)

$$
\underbrace{\rho c_{\mu} \frac{\partial T}{\partial t}}_{I}+\underbrace{\rho c_{\mu} U_{i} \frac{\partial T}{\partial x_{i}}}_{I I}=-\underbrace{P \frac{\partial U_{i}}{\partial x_{i}}}_{I I I}+\underbrace{\lambda \frac{\partial^{2} T}{\partial x_{i}^{2}}}_{I V}-\underbrace{\tau_{i j}^{\frac{\partial U_{j}}{\partial x_{i}}}}_{V}
$$

"I: Local energy change with time, II: Convective term, III: Pressure work, IV: Heat flux (diffusion),V: Irreversible transfer of mechanical energy into heat" (Agarwal and Pitso, 2020)

The CAD design of finned tube heat exchanger is modelled with 2D symmetry and converted in .iges file format. The discretization of finned tube CAD model is accomplished with fine relevance setting and using hexahedral element type as shown in figure 2.

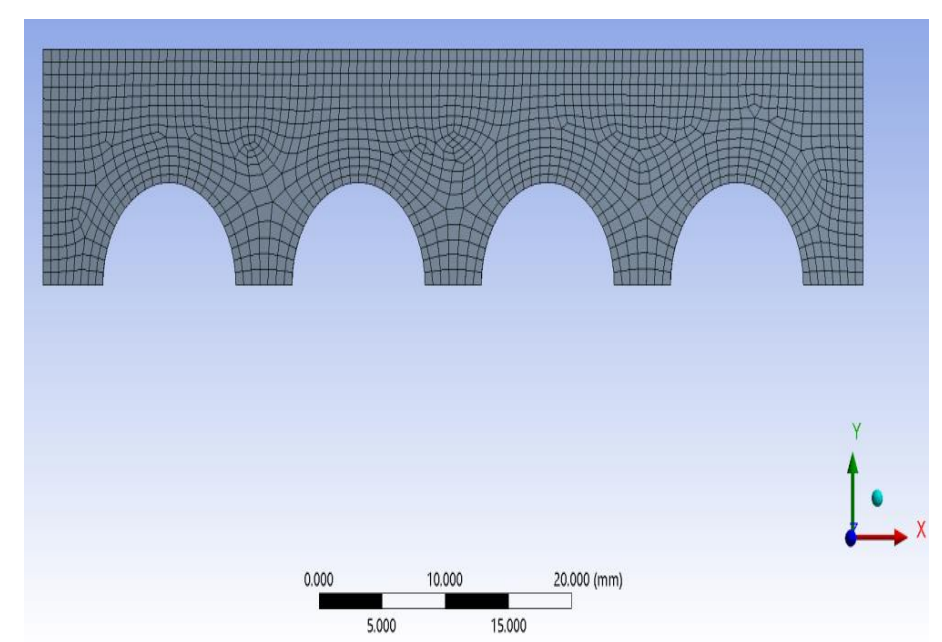

Figure 2 Meshed model in ANSYS and parameter setting.

Due to symmetric geometry, the loading conditions include symmetrical wall on side faces (shown by red arrows) as shown in figure 3. 


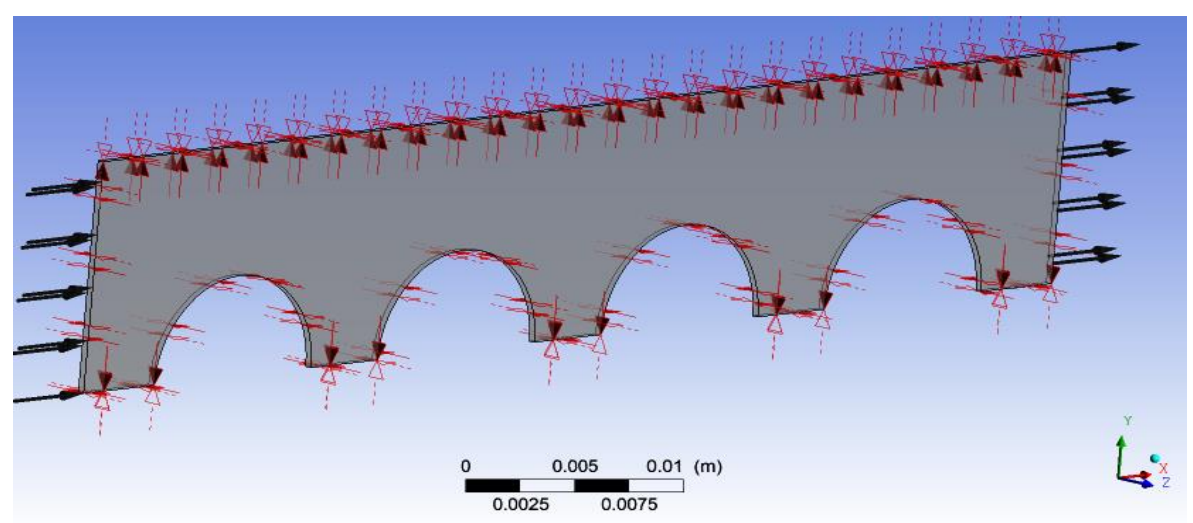

Figure 3 Boundary conditions

The wall on left face is applied with inlet boundary condition and wall on right face is applied with outlet boundary condition. The turbulence intensity and relative pressure difference is defined.

\section{RESULT AND DISCUSSION}

For this case we have used water as fluid without incorporating aluminum oxide nano particles and results are shown below. From temperature contour plotted in fig 4 (a) shows that fluid in contact with tube shows higher temperature as compared to fluid away from tube. There is non-uniformity in temperature distribution of fluid due to flow across tube banks. The heat transfer is due to turbulence and above tube banks uniform temperature with blue colored contours. The pressure distribution is shown in figure $4(\mathrm{~b})$ and variation of temperature is shown in figure $4(a)$.

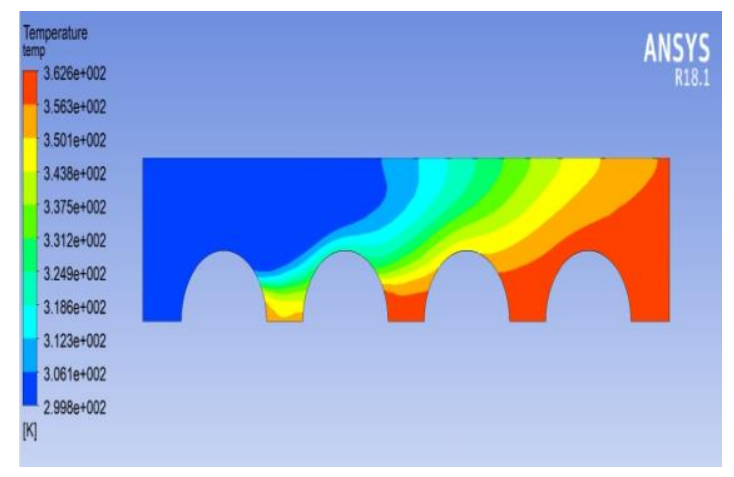

(a)

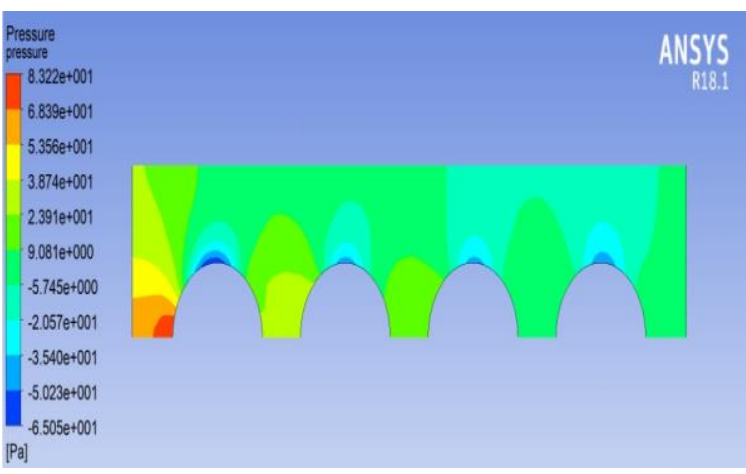

(b)

Figure 4 Plot for water, Temperature plot (a) and Pressure Contour (b) 
For other points negative pressure is developed and ranges from -65.3 $\mathrm{Pa}$ to $83.5 \mathrm{~Pa}$ max value. The temperature plot obtained for $\mathrm{ZnO}$ is very different as that of using water as fluid. Here maximum temperature shown by red colour is developed across entire fluid exit. The presence of dispersed $\mathrm{ZnO}$ particles in water causes low temperature near inlet. The maximum temperature obtained is $369 \mathrm{~K}$ which is much higher as compared to water as fluid as shown in fig. 5 (a). The pressure contour as shown in fig. 5 (b) is similar as that of water, but difference lies in maximum and minimum values.

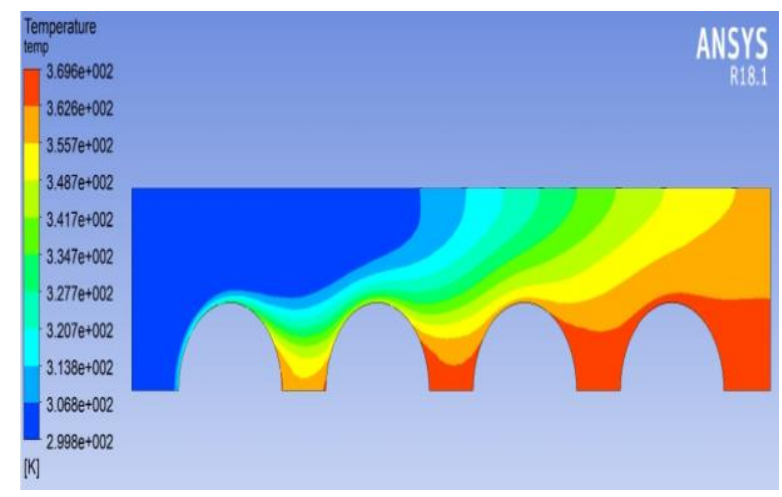

(a)

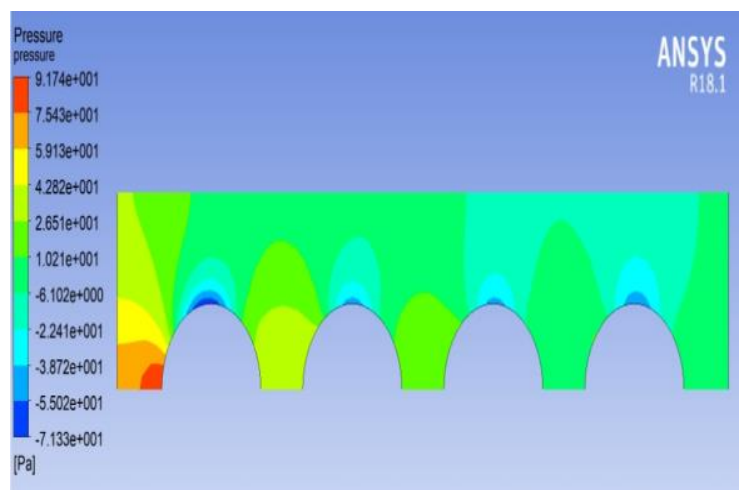

(b)

Figure 5 Plot for $\mathrm{ZnO} /$ water .02, Temperature contour (a) and Pressure Contour (b)

The region near inlet shows higher pressure with magnitude of 91Pa compressive (red color). The upper portion of tube experiences tensile pressure of magnitude $71 \mathrm{~Pa}$ (blue color).

The Nusselt number rises linearly with growth in Reynolds number as shown in fig. 6 (a) and fig. 6 (b) respectively.

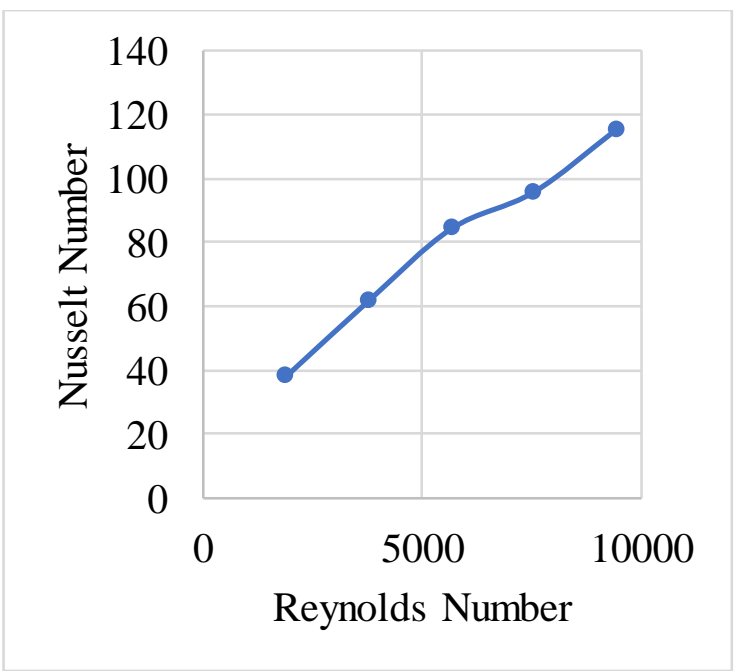

(a)

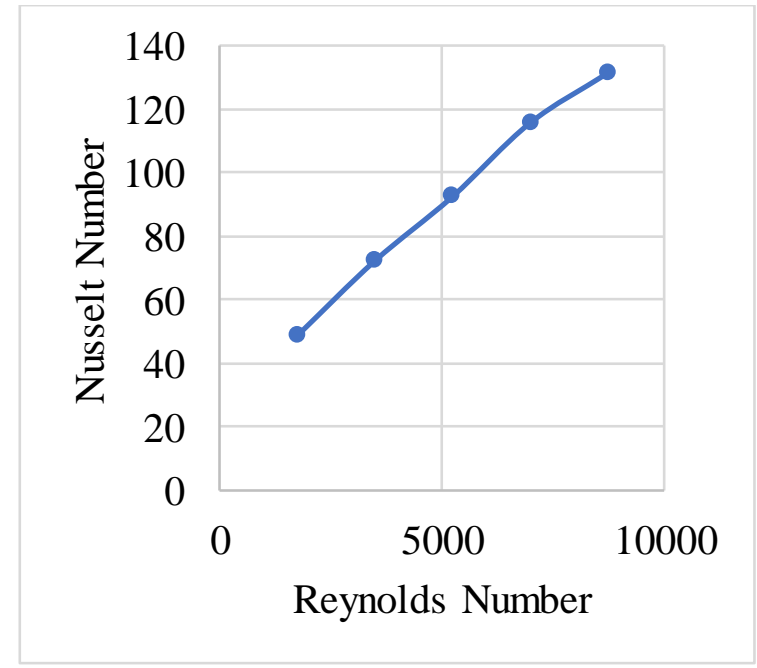

(b)

Figure 6 Nusselt number vs Re number for Water (a) for $\mathrm{ZnO} /$ water .02 (b) 
The Nusselt number of water increased linearly up-to $.6 \mathrm{~m} / \mathrm{s}$ fluid velocity and maximum Nusselt number is observed at $1 \mathrm{~m} / \mathrm{s}$. The pressure drop increases parabolically with increase in Reynolds number as shown in fig. 7 (a). The highest-pressure drop is of magnitude $775.35 \mathrm{~Pa}$ at $1 \mathrm{~m} / \mathrm{s}$ fluid velocity. Nusselt number vs Reynolds number for $\mathrm{ZnO} /$ water .04 is indicated in fig. 7 (b).

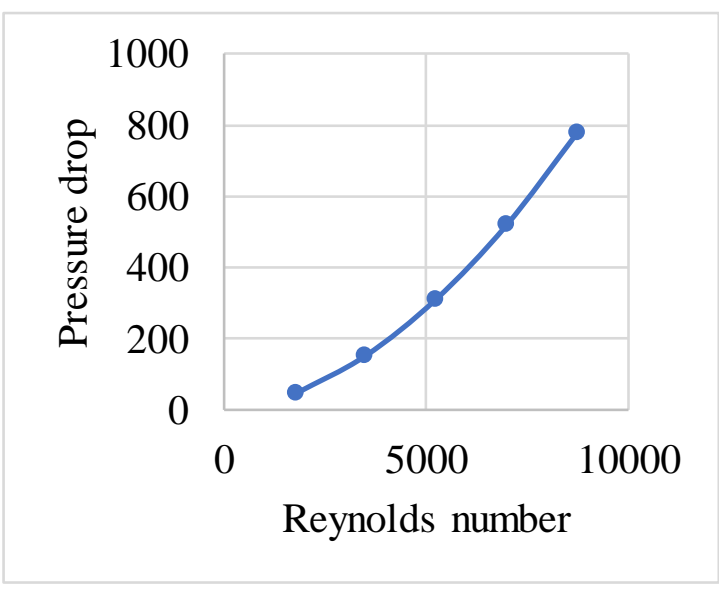

(a)

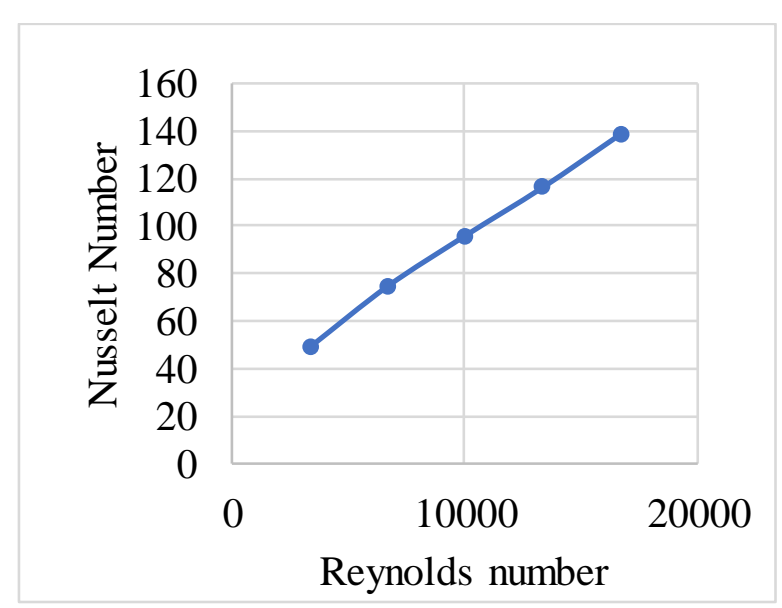

(b)

Figure 7 Plot for $\mathrm{ZnO}$ / water .02, Pressure drops vs $\mathrm{Re}$ (a) and $\mathrm{Nu}$ vs $\mathrm{Re}$

The heat transfer rate increases with increase in fluid velocity. The increase in Nusselt number can be attributed to higher heat transfer with increase in fluid velocity. Pressure drop vs Reynolds number graph for $\mathrm{ZnO} /$ water .04 is shown in fig. 8 (a) while Fig. 8 (b) shows Nusselt number vs Reynolds number for $\mathrm{ZnO} /$ water .07 .

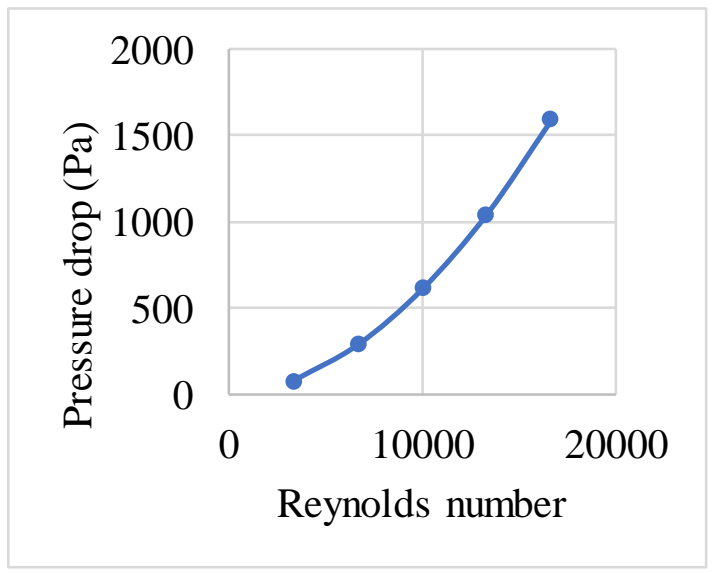

(a)

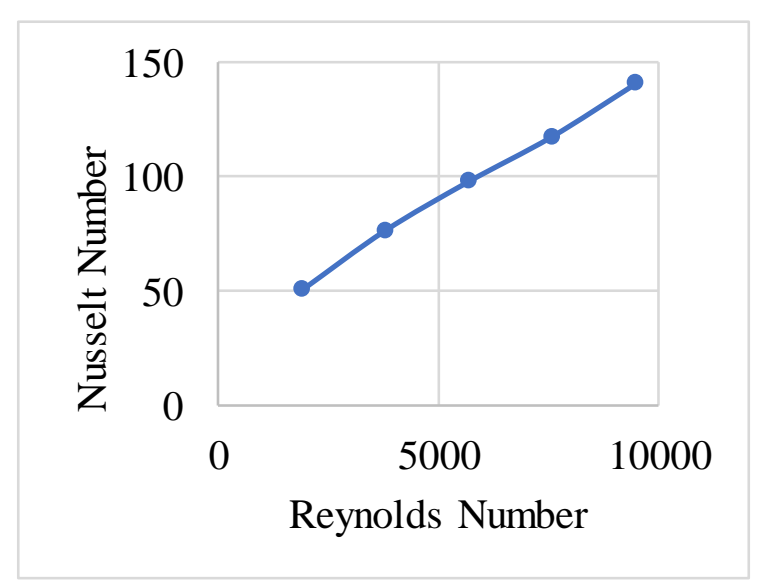

(b)

Figure 8 Plot for $\mathrm{ZnO}$ / water .04, Pressure drops vs $\mathrm{Re}$ (a) and $\mathrm{Nu}$ vs $\mathrm{Re}$ for $\mathrm{ZnO} /$ water .07 Figure 9 shows pressure drop vs Reynolds number graph for $\mathrm{ZnO} /$ water .07. The Nusselt number comparison between different volume fractions of nanofluids is shown in figure 10 . 


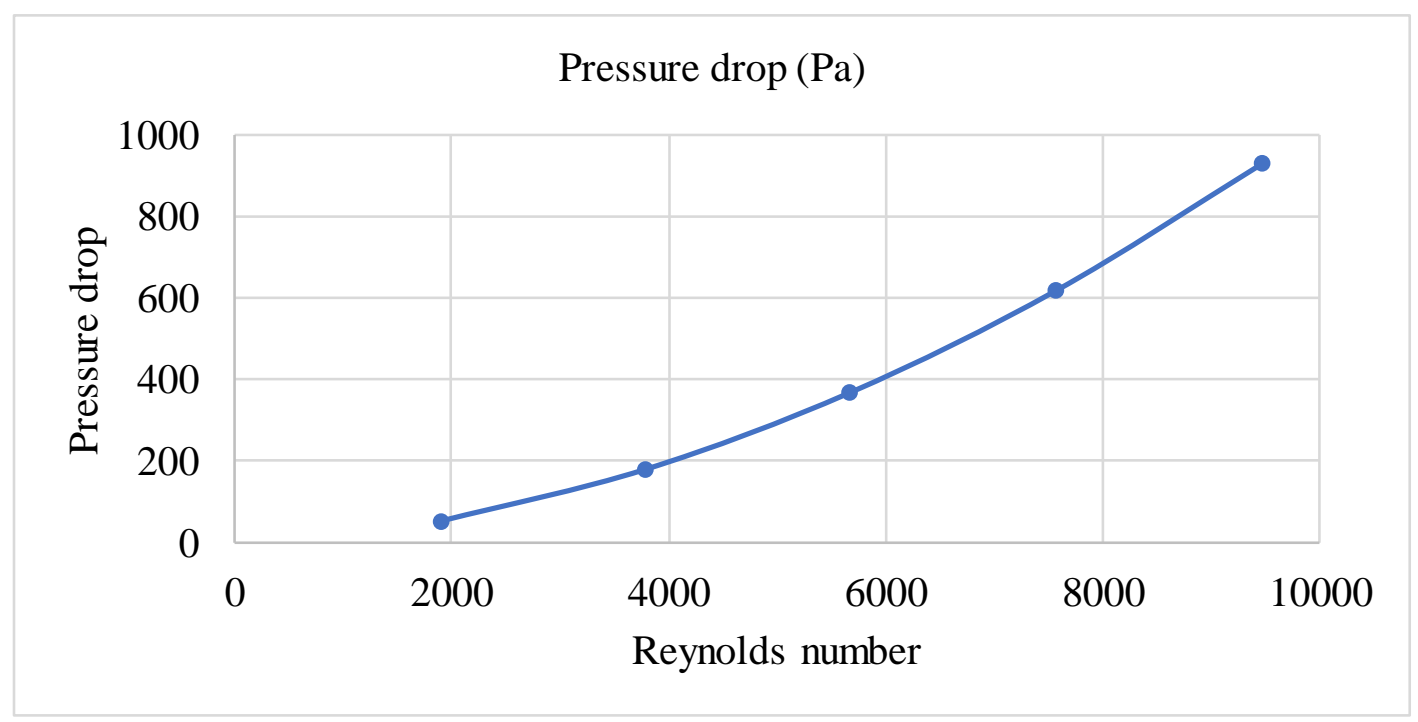

Figure 9 Pressure drop vs $\mathrm{Re}$ for $\mathrm{ZnO} /$ water .07

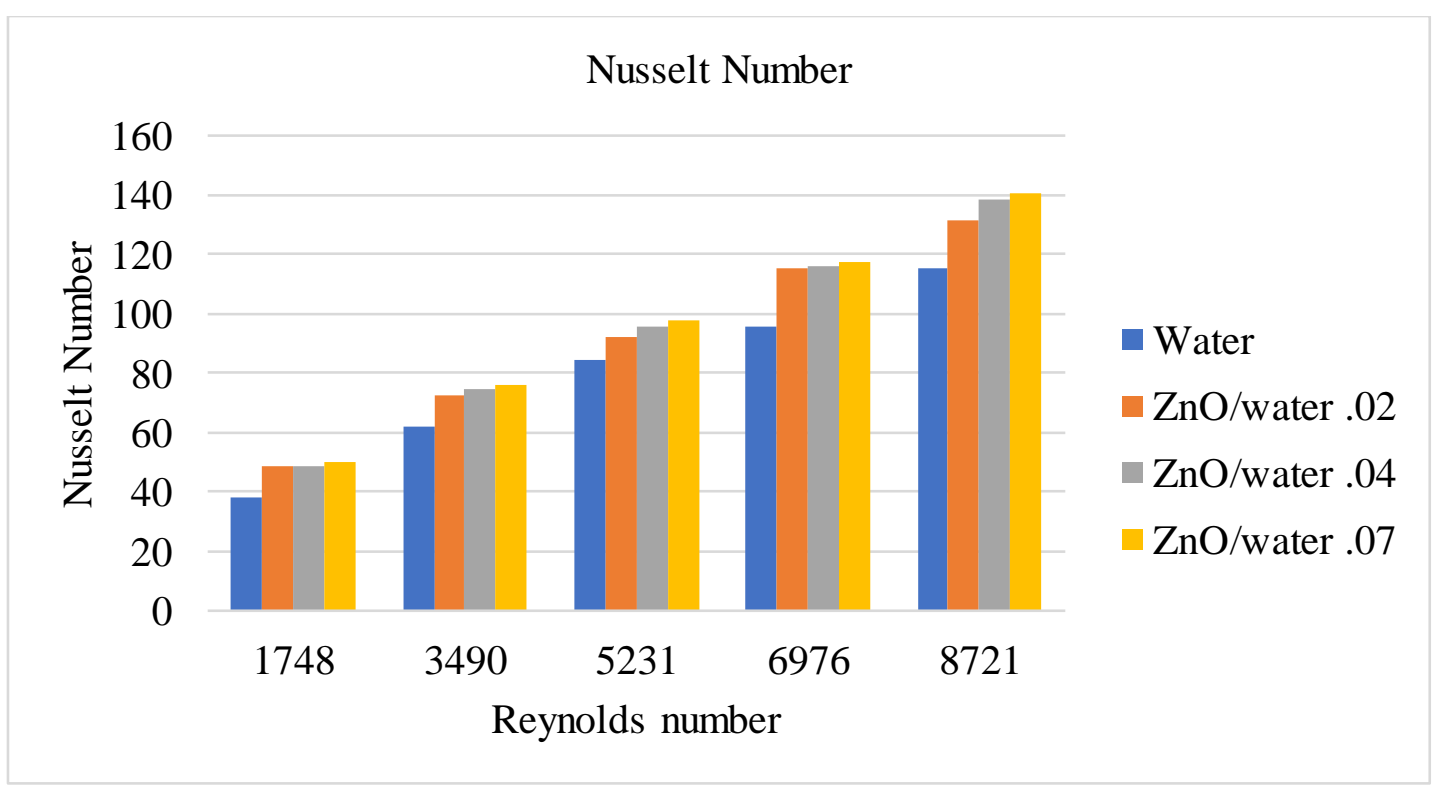

Figure 10 Nusselt number comparison for different volume fraction.

The minimum Nusselt number is observed using water as base fluid which increased with increase in volume fraction of nano fluids. The increase in concentration of nanoparticles helps to achieve higher rate of heat transfer. Drop in pressure with any concentration of nanofluids is higher than base fluid i.e., water for all Reynolds number as shown in figure 11 . 


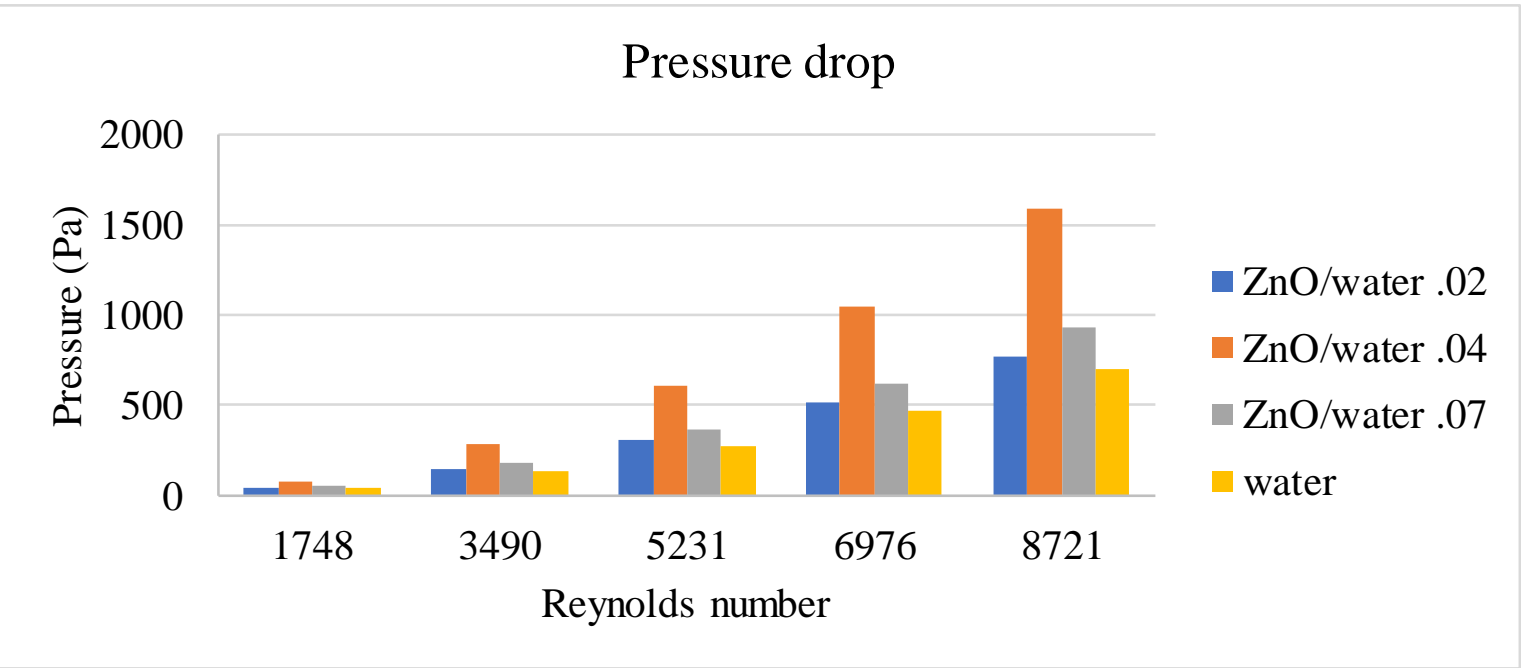

Figure 11 Pressure drop comparison for different volume fraction of $\mathrm{ZnO}$

\section{CONCLUSION}

The results obtained from CFD simulation of finned tube heat exchanger are encouraging. The use of nanofluids for heat exchangers have shown enhancement in heat transfer characteristics. By increasing volume fraction of $\mathrm{ZnO}$, the Nusselt number increased. The maximum Nusselt number is obtained for $\mathrm{ZnO} /$ water .07 composition and minimum Nusselt number is obtained for water (without any nanoparticles). However, the increase in heat transfer rate is accompanied with increase in pressure drop which increases pumping power requirement. The $\mathrm{ZnO} /$ water nanofluid with .02 volume faction has shown highest pumping power requirement. The SSG shear stress transport turbulence model has given reasonably good fluid flow predictions.

With the technological advancement in synthesis process of nanofluids the other type of nanofluids like $\mathrm{CuO} /$ water, $\mathrm{TiO}_{2} /$ water can be investigated for various types of heat exchangers. The turbulence model used for numerical analysis has significant effect on results generated i.e., temperature distribution, flow pattern and pressure plot. Different types of turbulence model available in CFD can be investigated for finned tube heat exchanger application.

\section{REFERENCES}

Afzal, Asif, Samee A. D. Mohammed, and Razak R. K. Abdul. 2019. Experimental Investigation of Thermal Performance of Engine Coolant Oil and Water in Helical Coil Heat Exchanger. Journal of Engineering Research (Kuwait) 7(2):333-51. 
Agarwal, A., O. B. Molwane, and I. Pitso. 2021. Analytical Investigation of the Influence of Natural Gas Leakage \& Safety Zone in a Pipeline Flow. Materials Today: Proceedings 39:547-52.

Agarwal, A., and L. Mthembu. 2020. CFD Analysis of Conical Diffuser under Swirl Flow Inlet Conditions Using Turbulence Models. Materials Today: Proceedings 27(2):135055.

Agarwal, A., and I. Pitso. 2020. Modelling \& Numerical Exploration of Pulsejet Engine Using Eddy Dissipation Combustion Model. Materials Today: Proceedings 27(2):134149.

Burnett, Mark E., and Steven Q. Wang. 2011. Current Sunscreen Controversies: A Critical Review. Photodermatology, Photoimmunology \& Photomedicine 27(2):58-67.

Gupta, Munish, Vinay Singh, Rajesh Kumar, and Z. Said. 2017. A Review on Thermophysical Properties of Nanofluids and Heat Transfer Applications. Renewable and Sustainable Energy Reviews 74:638-70.

Gupta, Naveen Kumar, Arun Kumar Tiwari, and Subrata Kumar Ghosh. 2018. Heat Transfer Mechanisms in Heat Pipes Using Nanofluids - A Review. Experimental Thermal and Fluid Science 90:84-100.

Kulkarni, Devdatta P., Debendra K. Das, and Ravikanth S. Vajjha. 2009. Application of Nanofluids in Heating Buildings and Reducing Pollution. Applied Energy 86(12):256673.

Kusworo, Tutuk D., Andri C. Kumoro, Budiyono, Qudratun, Bastian Widodo, Bilal T. Prabowo, and Dani P. Utomo. 2020. Enhancement of Nanohybrid PES-Nanosilica Performance for $\mathrm{CO} 2 / \mathrm{CH} 4$ Separation through Combined UV Irradiation and Thermal Annealing Treatments. Journal of Engineering Research (Kuwait) 8(3):17-30.

Lapotko, Dmitri. 2009. Plasmonic Nanoparticle-Generated Photothermal Bubbles and Their Biomedical Applications. Nanomedicine 4(7):813-45.

Maier-Hauff, Klaus, Ronny Rothe, Regina Scholz, Uwe Gneveckow, Peter Wust, Burghard Thiesen, Annelie Feussner, Andreas von Deimling, Norbert Waldoefner, Roland Felix, and Andreas Jordan. 2007. Intracranial Thermotherapy Using Magnetic Nanoparticles Combined with External Beam Radiotherapy: Results of a Feasibility Study on Patients with Glioblastoma Multiforme. Journal of Neuro-Oncology 81(1):5360. 
Mohammad, Akram. 2021. Effect of Added Struts and Intake Velocity on Fl Ame Stabilization in Supersonic Combustors. 9(March):247-60.

Nuntaphan, A., T. Kiatsiriroat, and C. C. Wang. 2005. Air Side Performance at Low Reynolds Number of Cross-Flow Heat Exchanger Using Crimped Spiral Fins. International Communications in Heat and Mass Transfer 32(1):151-65.

Paria, S., A. A. D. Sarhan, M. S. Goodarzi, S. Baradaran, B. Rahmanian, H. Yarmand, M. A. Alavi, S. N. Kazi, and H. S. C. Metselaar. 2015. Indoor Solar Thermal Energy Saving Time with Phase Change Material in a Horizontal Shell and Finned-Tube Heat Exchanger. Scientific World Journal 2015.

Pongsoi, Parinya, Santi Pikulkajorn, Chi-Chuan Wang, and Somchai Wongwises. 2011. Effect of Fin Pitches on the Air-Side Performance of Crimped Spiral Fin-and-Tube Heat Exchangers with a Multipass Parallel and Counter Cross-Flow Configuration. International Journal of Heat and Mass Transfer 54(9):2234-40.

Pongsoi, Parinya, Patcharapit Promoppatum, Santi Pikulkajorn, and Somchai Wongwises. 2013. Effect of Fin Pitches on the Air-Side Performance of L-Footed Spiral Fin-and-Tube Heat Exchangers. International Journal of Heat and Mass Transfer $59: 75-82$.

Sahnoune, Khaled, Abderrahmane Benbrik, Ahmed S. Mansour, and Rekik Oussama. 2020. Flow Simulation and Performance Analysis of a Drilling Turbine. Journal of Engineering Research (Kuwait) 8(3):255-70.

Sharma, Tushar, A. Leela Mohana Reddy, T. S. Chandra, and S. Ramaprabhu. 2008. Development of Carbon Nanotubes and Nanofluids Based Microbial Fuel Cell. International Journal of Hydrogen Energy 33(22):6749-54.

Su, Wei, Yi Xing, Hongzhi Ma, Rui Li, Cunyi Song, and Zhensong Tong. 2019. Numerical Simulation of a New Horizontal Spray Tower for Sintering Flue Gas Desulfurization. Journal of Engineering Research (Kuwait) 7(4):1-17.

Suganthi, K. S., and K. S. Rajan. 2017. Metal Oxide Nanofluids: Review of Formulation, Thermo-Physical Properties, Mechanisms, and Heat Transfer Performance. Renewable and Sustainable Energy Reviews 76:226-55.

Sundar, L. Syam, K. V Sharma, Manoj K. Singh, and A. C. M. Sousa. 2017. Hybrid Nanofluids Preparation, Thermal Properties, Heat Transfer and Friction Factor - A Review. Renewable and Sustainable Energy Reviews 68:185-98. 
Taylor, Robert, Sylvain Coulombe, Todd Otanicar, Patrick Phelan, Andrey Gunawan, Wei Lv, Gary Rosengarten, Ravi Prasher, and Himanshu Tyagi. 2013. Small Particles, Big Impacts: A Review of the Diverse Applications of Nanofluids. Journal of Applied Physics 113(1):11301.

Vékás, Ladislau, Doina Bica, and Mikhail V Avdeev. 2007. Magnetic Nanoparticles and Concentrated Magnetic Nanofluids: Synthesis, Properties and Some Applications. China Particuology 5(1):43-49.

Wen, Mao-Yu, and Ching-Yen Ho. 2009. Heat-Transfer Enhancement in Fin-and-Tube Heat Exchanger with Improved Fin Design. Applied Thermal Engineering 29(5):1050-57. 